\title{
ESTUDOS BACTERIOLOGICOS E SOROLOGICOS DE UM SURTO DE PESTE NO ESTADO DA PARAIIBA, BRASIL
}

\author{
ALZIRA MARIA PAIVA DE ALMEIDA, DARCI PASCOAL BRASIL, NILMA CINTRA LEAL, \\ MARIA ELIANE BEZERRA DE MELO, ROSA VIRGININIA BATISTA DO RÉGO* \& CÉLIO \\ RODRIGUES DE ALMEIDA
}

Centro de Pesquisas Aggeu Magalhäes - FIOCRUZ, Departamento de Microbiologia, Caixa Postal 7472 ,
50730 Recife, PE, Brasil * SUCAM, Rua Geraldo Von Shosten s/no, Jaguaribe, João Pessoa, PB, Brasil

Bacteriological and serological studies of a plague outbreak in the Paraíba State, Brazil During a plague outbreak in the Borborema Plateau focus (Paraiba), bacteriological and serological studies were carryed out in material from 452 patients (48 positives), 1,938 rodents and other small mammals (75 positives), 4,756 dogs (141 positives) and 2,047 cats (57 positives) obtained from 41 counties (out of which, 21 produced positive samples).

Twenty Yersinia pestis strains isolated from material from 3 patients and 17 rodents, displayed biochemical reactions, virulence factors, antibiotic susceptibility and animal experimental pathogenicity similar to those observed in strains previously isolated.

According to our findings this recent plague outbreak did not exhibite different factors from those observed during prior outbreaks in other plague foci in the northeast of Brazil.

Key words: plague outbreak - Yersinia pestis - humans - rodents - domestic carnivors - bacteriology serology

-A peste foi registrada pela primeira vez, no Estado da Para iba, em 1912. Sua entrada no Brasil ocorreu em 1899 pelo porto de Santos em conseqüência da epidemia originada na China, no fim do século passado e que se propagou de Hong-Kong para as mais importantes cidades portuárias. No Brasil, várias cidades do litoral foram infectadas e em seguida algumas cidades do interior. Disseminando-se, posteriormente, pela zona rural, a infecção encontrou condiçðes favoráveis à formação de diversos focos naturais.

Graças a medidas sanitárias adequadas, a peste foi eliminada das cidades mas ficou focalizada entre os roedores, no meio rural, de onde não se pôde erradicar (Freitas, 1970).

Baseado na distribuição dos casos humanos da doença registrados pelo Serviço Nacional de Peste (SNP) Baltazard (1968), mostrou que, na Paraiba, a peste está focalizada em duas áreas independentes: nos municípios de Manaíra e Princesa Isabel, que junto com o município de Triunfo (pertencente ao Estado de Pernambuco) formam um pequeno foco, denominado

Recebido em 29 de novembro de 1988. Aceito em 22 de fevereiro de 1989. por aquele autor, Foco de Triunfo. A outra área faz parte do foco designado por Baltazard (1968), Foco Leste de Pernambuco. Este foco é . bastante amplo e se estende pelo Planalto da Borborema e suas imediaçбes, abrangendo vánios municípios dos Estados do Rio Grande do Norte, Paraíba, Pernambuco e Alagoas. Em nossas publicaçð̌es anteriores (Almeida et al., $1985 ; 1987 \mathrm{a} ; 1988)$ preferimos adotar para este foco a denominação de Foco da Chapada ou do Planalto da Borborema.

Estudos realizados por Almeida et al. (1985; 1987a) permitiram detectar atividade pestosa nos roedores, na ausência de casos humanós, no Foco do Planalto da Borborema e em roedores e seus pulicídeos associada à infecção humana, no Foco de Triunfo (Almeida et al., 1981; 1985).

Este artigo relata os resultados dos trabalhos desenvolvidos após um surto de peste que irrompeu em setembro de 1986, na área paraibana do Foco do Planalto da Borborema.

\section{MATERIAIS E MËTODOS}

Pesquisa da Yersinia pestis em material de origem humana e de roedores: as amostras para 
exame foram obtidas, pelas equipes da Campanha Contra a Peste, da Diretoria Regional da Paraiba, da Superintendência de Campanhas, do Ministério da Saúde (CCP/DR/PB/SUCAM/ MS) de maneira já descrita (Almeida et al., 1981 ; 1986) e processadas segundo a metodologia de Baltazard et al. (1956) Bahmanyar \& Cavanaugh (1976), Karimi (1978) e Almeida et al. $(1986 ; 1987 a)$.

Estudo das cepas de Yersinia pestis: a caracterização bioquímica e a determinação in vitro dos fatores de virulência foram realizadas usando os métodos recomendados por Bahmanyar \& Cavanaugh (1976). A virulência para cobaias, camundongos albinos "outbred" e roedores silvestres (Oryzomys subflavus) de uma colônia desenvolvida no laboratório, foi estudada seguindo a metodologia descrita por Karimi et al. (1974a), Butler et al. (1980) e Almeida et al. (1986), calculando-se a DL50 e a DI50 pelo método de Reed \& Muench (1938). A sensibilidade aos antibióticos foi determinada pelo método de difusão (Bauer et al., 1966) em Agar Mueller-Hinton e discos das seguintes drogas antibacterianas nas respectivas concentrações: tetraciclina $(30 \mathrm{mcg})$, ampicilina $(10 \mathrm{mcg})$, rifampicina $(5 \mathrm{mcg})$, ácido nalidixo (30 mcg), carbenicilina (100 mcg) cloranfenicol $(30 \mathrm{mcg})$ e sulfazoltrim $(25 \mathrm{mcg})$. Para efeito comparativo, foram estudadas em paralelo, as sete cepas do Planalto da Borborema originadas de roedores dos municípios de Natuba e Salgado de São Félix (PB) encontrados infectados no período de 1979 a 1982 independentemente de casos humanos da doença (Almeida et al., 1985).

Estudos sorológicos: soros dos pacientes, carnívoros domésticos (cães e gatos), roedores e outros pequenos mamíferos (os marsupiais Monodelphis $d$. domestica e Didelphis albiventris) obtidos pela CCP/DR/PB/SUCAM/MS, de modo descrito anteriormente (Almeida et al., $1981 ; 1987 b ; 1988)$, foram testados por hemaglutinação passiva (PHA) para anticorpos específicos contra a fraçāo antigênica purificada (F1A) da $Y$. pestis e inibição da hemaglutinação (PHI), recomendados pelo "WHO Expert Committee on Plague" (1970). O antígeno (F1A) foi obtido segundo Baker et al. (1952).

\section{RESULTADOS}

Peste humana: foram analisadas amostras de material, obtidas de 452 pacientes ( 253 do sexo masculino e 199 do sexo feminino) oriundos de 41 municípios do Estado da Paraíba. A distribuição dos pacientes examinados e pacientes positivos por município, encontra-se na Tabela I. A Tabela II mostra a distribuição mensal dos pacientes no período de setembro de 1986 a dezembro de 1987. Material de 395 pacientes foi submetido a testes sorológicos, de nove a provas bacteriológicas e de 48 a exames bacteriológicos e sorológicos. O material dos 57 pacientes examinados por técnicas bacteriológicas compunha-se de 49 amostras de suco bubonático (duas positivas), quatro amostras de pus colhidas nas flictenas, resultantes provavelmente das picadas das pulgas vetoras (uma positiva), três amostras de esputo (negativas) e medula da falange de quatro cadáveres (negativas). As amostras haviam sido colhidas entre o 1 \% e o $49^{\circ}$ dias após o aparecimento dos primeiros sintomas da doença (21 nos primeiros cinco dias, 23 do $6^{\circ}$ ao $49^{\circ}$ dia e 11 sem informação). Das três amostras positivas, duas haviam sido colhidas no $33^{\circ}$ dia depois dos primeiros sintomas e uma no $5^{\circ}$ dia.

Os testes sorológicos foram realizados ein 692 amostras obtidas de 443 pacientes, tendo sido colhidas pareadas de 249 pacientes; a primeira no dia da investigação realizada pela equipe da CCP/DR/PB/SUCAM/MS, no período de 0 a 90 dias depois dos primeiros sintomas e a segunda até 600 dias mais tarde. De 196 pacientes foi obtida apenas uma amostra, sendo 98 , no período de 0 a 4 dias do início da doença, 54 de 5 a 14 dias, 17 , de 15 a 90 dias e 25 , sem informação. Do total das 692 amostras examinadas, 238 foram obtidas antes do 5 \% dia dos primeiros sintomas, 127 de 5 a 14 dias, 280 , após 15 dias e 47 sem informação. Quarenta e sete pacientes dos 452 examinados, tiveram sorologia positiva, sendo 27 logo ao primeiro exame realizado do $2^{\circ}$ ao $17^{\circ}$ dia do início da doença, não sendo mais realizado o segundo exame. Doze pacientes com resultados negativos ao primeiro exame realizado entre o 10 e o 5 \% dia da doença, mostraram soro-conversão em amostras obtidas posteriormente entre o 24 \% e o 4809 dia. Dos sete pacientes com amostras pareadas positivas, três mostraram elevação do título de anticorpos entre a primeira e a segunda amostra; em dois não houve alteração do título (um paciente manteve o título de $1 / 16$, que é considerado o mínimo significativo, nas duas amostras obtidas respectivamente ao 3 ? e $420^{\circ}$ dia do início da doença) e em dois foi observada queda do título. A diminuição do 


\section{TABELA I}

Distribuição, por município, dos pacientes, carnívoros domésticos, roedores e outros pequenos mamíferos examinados no período de setembro de 1986 a dezembro de 1987

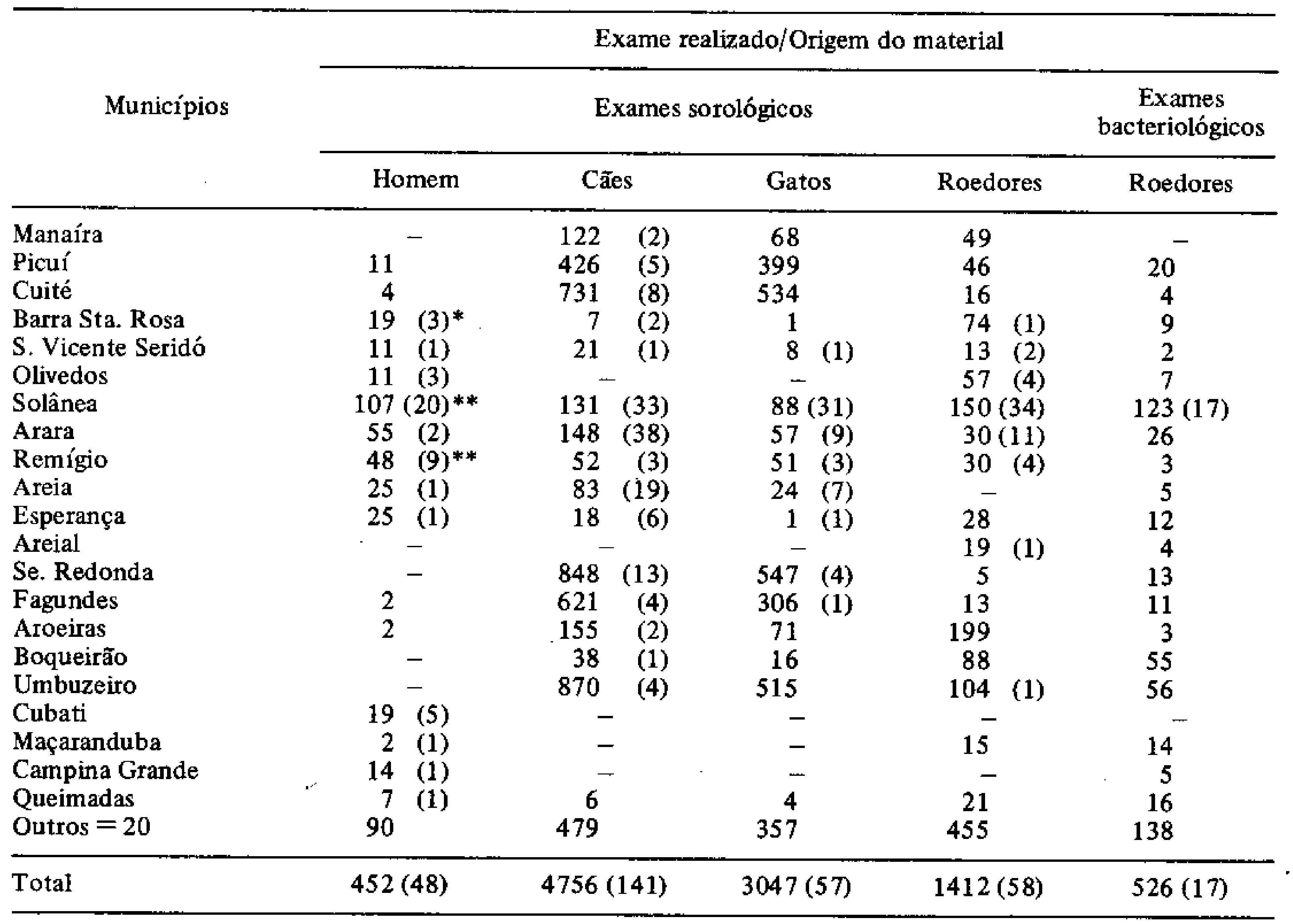

* 1 paciente negativo por teste sorológico e positivo por exame bacteriológico.

** 1 paciente positivo por exame bacteriológico e sorológico.

( ) Positivos.

título de anticorpos foi notada em outro paciente que ao primeiro exame realizado no 15 ? dia após o início da doença, apresentou um título de $1 / 32$ não sendo detectados anticorpos por ocasião do segundo exame no $60^{\circ}$ dia.

Peste dos roedores e outros pequenos mamiferos: baço, fígado, sangue ou medula dos fêmures de 526 roedores e pequenos mamíferos silvestres (marsupiais) foram analisados por cultivo e/ou inoculações, no período de setembro de 1986 a dezembro de 1987, tendo sido encontrados 17 roedores positivos.

A distribuição por espécie desses animais encontra-se na Tabela III.

Exames sorológicos foram realizados em 1.362 roedores ( 53 positivos) e 50 marsupiais (5 positivos).
A distribuição por espécie dos animais analisados por testes sorológicos encontra-se na $\mathrm{Ta}$ bela IV.

Nas Tabelas I e II observa-se a distribuição por município e por mês dos animais examinados por métodos bacteriológicos e sorológicos.

Exames sorológicos nos carnivoros domésti$\cos$ (cães e gatos): no período de setembro de 1986 a dezembro de 1987 foram analisadas amostras de soro de 4.756 cães (141 positivas) e 3.047 gatos ( 57 positivas).

As Tabelas I, II e IV mostram a distribuição por município, mês e ano dos animais examinados e animais portadores de anticorpos antipestosos. 
TABELA II

Distribuiçāo mensal dos pacientes, camívoros domésticos, roedores e ou tros pequenos mamíferos examinados no período de setembro de 1986 a dezembro de 1987

\begin{tabular}{|c|c|c|c|c|c|}
\hline \multirow{3}{*}{ Meses } & \multicolumn{5}{|c|}{ Exame realizado/Origem do material } \\
\hline & \multicolumn{4}{|c|}{ Exames sorológicos } & \multirow{2}{*}{$\begin{array}{c}\begin{array}{c}\text { Exames } \\
\text { bacteriológicos }\end{array} \\
\text { Roedores }\end{array}$} \\
\hline & Homem & Cães & Gatos & Roedores & \\
\hline Setembro & $21(10)$ & 23 & 29 & 80 & - \\
\hline Outubro & $27(11)$ & $60 \quad(14)$ & $65(19)$ & $105(26)$ & $91(17)$ \\
\hline Novembro & $111(10)$ & $136(31)$ & $60(8)$ & $173(21)$ & 66 \\
\hline Dezembro & $117(6)$ & $96 \quad(8)$ & $57 \quad(1)$ & 109 & 72 \\
\hline Janeiro & $65 \quad(2)$ & $183(27)$ & $44 \quad(7)$ & 42 (1) & 53 \\
\hline Fevereiro & $30 \quad(5)$ & $127 \quad(2)$ & 76 & 77 & 64 \\
\hline Março & 9 & 152 (11) & 51 (5) & 25 & 35 \\
\hline Abril & $6(2)$ & $55 \quad(6)$ & $28 \quad(8)$ & - & 5 \\
\hline Maio & 18 (2) & 561 & 375 & 101 & 4 \\
\hline Junho & 9 & 619 & 385 (1) & 82 & 32 \\
\hline Julho & 7 & $821 \quad(6)$ & 514 (1) & 36 & 25 \\
\hline Agosto & 7 & 601 & 440 & 220 & 32 \\
\hline Setembro & 11 & $586 \quad(14)$ & $456 \quad(5)$ & 135 (3) & 30 \\
\hline Outubro & 6 & $665 \quad(7)$ & $430 \quad(2)$ & 129 (7) & 17 \\
\hline Novembro & 5 & 43 & 19 & 98 & - \\
\hline Dezembro & 3 & 28 & 18 & - & - \\
\hline Total & $452(48)$ & $4576(141)$ & $3047(57)$ & $1412(58)$ & $526(17)$ \\
\hline
\end{tabular}

( ) Positivos.

\section{TABELA III}

Distribuição dos roedores e ou tros pequenos mamíferos submetidos a provas bacteriológicas no período de se tembro de 1986 a dezembro de 1987

\begin{tabular}{lrl}
\hline \multicolumn{1}{c}{ Espécies } & Examinados (positivos) \\
\hline Bolomys lasiurus & $206(6)$ \\
Oryzomys subflavus & $52(4)$ \\
Oryzomys eliurus & 1 \\
Calomys callosus & 5 \\
Rattus r. alexandrinus & 8 \\
Rattus $r$. frugivorus & $65(6)$ \\
Mus. m. brevirostris & 21 \\
Trichomys apereoides & 46 \\
Holochilus sciureus & $5(1)$ \\
Galea s. wellsi & 88 \\
Monodelphis d. domestica* & 8 \\
Didelphis albiventris* & 1 \\
S/informaçöes & 20 \\
\hline Total & $526(17)$ \\
\hline
\end{tabular}

* Marsupiais.

Isolamento de Y. pestis: foram isoladas 20 cepas de $Y$. pestis de material obtido de três pacientes e 17 roedores (Tabela $\mathrm{V}$ ).
As amostras foram conservadas em camada alta de Agar a $4{ }^{\circ} \mathrm{C}$, como relatado em publicação anterior (Almeida et al., 1985) e identificadas com a sigla P. (Peste), PB (Unidade da Federação de origem do material) seguidos do número de ordem dos isolamentos efetuados previamente pela equipe em material de outros focos.

As 20 cepas recém-isoladas apresentaram perfil bioquímico semelhante ao das sete cepas antigas, com as seguintes características: motilidade negativa, fermentam a glicose (sem produção de gás) e o manitol, não fermentam a lactose, sacarose nem a glicerina. Reduzem o nitrato a nitrito, não produzem indol nem $\mathrm{H}_{2} \mathrm{~S}$, não hidrolisam a uréia e não possuem a enzima lisina descarboxilase.

As cepas estudadas mostraram igual sensibilidade a todas as drogas testadas, exceto a P.PB 862 (originada do pus de uma flictena de um paciente do município de Solânea) que apresentou resistência à ampicilina $(10 \mathrm{mcg})$.

Os fatores de virulência conhecidos da $Y$. pestis (P, VW, PFC e FI) foram encontrados 


\section{TABELA IV}

Origem do material analisado por testes sorológicos no período de setembro de 1986 a dezembro de 1987

\begin{tabular}{lrrrrrrrrrr}
\hline \multirow{2}{*}{ Fonte } & \multicolumn{3}{c}{$1986^{*}$} & \multicolumn{3}{c}{$1987^{* *}$} & \multicolumn{3}{c}{ Total } \\
\cline { 2 - 11 } & Exam. & (Posit.) & $\%$ & Exam. & (Posit.) & $\%$ & Exam. & (Posit.) & $\%$ \\
\hline Homem & 276 & $(37)$ & 13,4 & 176 & $(11)$ & 6,2 & 452 & $(48)$ & 10,6 \\
Cão & 315 & $(53)$ & 16,8 & 4441 & $(88)$ & 1,9 & 4756 & $(141)$ & 2,9 \\
Gato & 211 & $(28)$ & 13,2 & 2836 & $(29)$ & 1,0 & 3747 & $(57)$ & 1,8 \\
Rattus r. alexandrinus & 104 & $(8)$ & 7,6 & 121 & - & - & 225 & $(8)$ & 3,5 \\
Rattus r. frugivorus & 143 & $(10)$ & 6,9 & 224 & $(1)$ & 0,4 & 367 & $(11)$ & 2,9 \\
Galea s. wellsi & 199 & $(24)$ & 12,0 & 502 & $(10)$ & 1,9 & 701 & $(34)$ & 4,8 \\
Trichomys apereoides & 5 & - & - & 64 & - & - & 69 & - & - \\
Monodelphis domestica & 8 & $(2)$ & 25,0 & 6 & - & - & 14 & $(2)$ & 14,3 \\
Didelphis albiventris & 8 & $(3)$ & 37,5 & 28 & - & - & 36 & $(3)$ & 8,3 \\
\hline
\end{tabular}

* Setembro a dezembro.

** Janeiro a dezembro.

TABELA V

Origem das cepas de Yersinia pestis isoladas

\begin{tabular}{llll}
\hline \multicolumn{1}{c}{ Município } & Fonte de material & Material & No de isolamentos \\
\hline Solânea & Homem & pústula & 1 \\
Barra Sta. Rosa & Homem & suco bubonático & 1 \\
Remígio & Homem & suco bubonático & 1 \\
Solânea & Bolomys lasiurus & fêmur & 2 \\
Solânea & Bolomys lasiurus & baço & 4 \\
Solânea & Oryzomys subflavus & baço & 4 \\
Solânea & Holochilus sciureus & baço & 1 \\
Solânea & Rattus r. frugivorus & baço & 1 \\
Solânea & Rattus r. frugivorus & fêmur & 5 \\
\hline
\end{tabular}

nas 27 cepas estudadas. Todas elas desenvolvem colônias pigmentadas (P) no meio Agar Vermelho Congo, produzem crescimento confluente no meio Agar Oxalato de Magnésio na temperatura de $28^{\circ} \mathrm{C}$ e inibição a $37^{\circ} \mathrm{C}(\mathrm{VW})$ e são capazes de coagular o plasma de coelho normal a $26^{\circ} \mathrm{C}$ (PFC). $\mathrm{O}$ antígeno $\mathrm{F} 1$ foi detectado por imunodifusão com anticorpo policlonal anti-F1 obtido em coelho.

Cobaias inoculadas pela via percutânea com as três cepas de origem humana (P.PB 862, P.PB 863 e P.PB 881), produzem lesões características no local de inoculaçāo e hipertrofia dos linfonodos relacionados ao ponto de inoculação que desaparecem no decorrer da segunda semana. Pela via subcutânea, as cobaias resistem a inóculos superiores a $3 \times 10^{5}$ bacilos.

Para os camundongos, a DL50 da cepa P.PB 862 pela via intraperitoneal foi igual a 632 bacilos e a DI50 menor que 20 bacilos.
Pela via subcutânea a DL50 foi maior que 10.000 bacilos e a DI50 igual a 25 bacilos. A DL50 e a DI50 para o $O$. subflavus foi menor que 10 bacilos pela via subcutânea com a cepa P.PB 862.

\section{DISCUSSĀO}

Após vários anos de atividade limitada aos roedores (Almeida et al., 1985; 1987a), a peste voltou a incidir entre a população humana, no Estado da Paraíba. A infecção foi comprovada por testes bacteriológicos e/ou sorológicos em material obtido de pacientes, carnivoros domésticos (cães e gatos) roedores e outros pequenos mamíferos oriundos de 21 municípios distribuidos em toda a extensão do Planalto da Borborema, correspondente ao Estado da Paraíba (Tabela I). Apesar do grande número de casos nessa área, no Foco de Triunfo não foi registrado nenhum caso humano, confirmando a constatação de Baltazard (1968) de que as ativida. 
des dos focos são independentes no tempo e no espaço.

Os primeiros casos humanos ocorreram em setembro de 1986, no município de Solânea e até maio de 1987 foram registrados 404 casos, sendo 48 comprovados laboratorialmente. Embora nenhum caso humano tenha sido confirmado por exames de laboratório após esse período (Tabela II), foi possivel encontrar anticorpos antipestosos em soro de roedores e carnívoros domésticos. O papel dos carnivoros nos focos pestosos do nordeste do Brasil, foi analisado em publicação anterior (Almeida et al., 1988).

Salientamos que o registro dos casos humanos $\dot{e}$ realizado com base na data do aparecimento dos primeiros sintomas da doença, enquanto que para os roedores e carnívoros, o registro é feito pela data da coleta do material para exame, de maneira que em relação a esses últimos, a infecção pode ser antiga ou recente. Anticorpos contra a $Y$. pestis podem ser detectados até cerca de 300 dias após a infecção, em cães e gatos (Rust et al., 1971).

Como observado em outros focos (Almeida et al., 1981; 1987b), os exames de laboratório de grande número de pacientes, considerados clinicamente suspeitos de peste, resultaram negativos. Material para exames bacteriológicos foi obtido de apenas 57 pacientes dos 452 registrados e cerca da metade dessas amostras foi colhida tardiamente. Quando se objetiva a identificação do bacilo, as amostras para exame devem ser colhidas nos primeiros dias da doença (Baltazard et al., 1956; Bahmanyar \& Cavanaugh, 1976). Quanto ao material para exames sorológicos, $34,4 \%$ foram obtidos precocemente, isto é, de 0 a 4 dias do início da doença. Segundo Butler \& Hudson (1977) anticorpos hemaglutinantes contra a F1A de $Y$. pestis tornam-se detectáveis após o $5^{\circ}$ dia da doença. Visando esclarecer o problema constituído pelos pacientes com diagnóstico clínico de peste e negativos pelo teste de hemaglutinação, Almeida et al. (1987b) empregaram sem sucesso o teste de aglutinação bacteriana, usando como antígeno 12 cepas de $Y$. pestis oriundas de fontes diversas. Por outro lado, durante um surto de peste humana, em 1982, no Foco da Serra de Baturité (Ceará), 55,93\% das amostras de soro obtidas dos pacientes revelaram-se positivas enquanto que no início do surto da $\mathrm{Pa}$ raíba, apenas $15,31 \%$ foram positivas e foi con- siderado que no primeiro caso houve um critério mais rigoroso no diagnóstico clínico dos casos e obtenção das amostras para exame (Almeida et al., 1988).

Analisando-se a Tabela II observa-se que a positividade diminuiu no ano de 1987. As amostras examinadas no período de setembro a dezembro de 1986, apresentam maior percentual de positividade que as de 1987 (Tabela IV). Para os roedores e camívoros, estas diferenças são também resultantes da metodologia empregada na obtenção das amostras. No início do surto, as colheitas de material para exames estavam mais concentradas no epicentro do foco, porém à medida que os casos humanos rareavam, os trabalhos foram sendo orientados para a sua periferia. Observando-se as Tabelas III e IV verifica-se que os exames bacteriológicos foram realizados em 10 espécies de roedores e duas de marsupiais, enquanto que apenas quatro espécies de roedores e duas de marsupiais foram submetidas a testes sorológicos. Para estes últimos, foram selecionadas as espécies resistentes à infecção pela $Y$. pestis (Rattus $r$. alexandrinus, Rattus $r$. frugivorus, Galea s. wellsi, Monodelphis domestica e Didelphis albiventris) além do Trychomis apereoides que é, ao contrário, extremamente sensivel (Karimi et al., 1974a, b). Hudson \& Kartman (1967) recomendam a pesquisa de anticorpos antipestosos nas espécies resistentes. Por outro lado, 0 isolamento do bacilo deve ser tentado preferencialmente entre os animais sensiveis que fazem septicemia e generalizam a infecção (Karimi et al., 1974a, b). Anticorpos antipestosos foram encontrados somente nas espécies resistentes e os 69 Trichomys analisados foram negativos (Tabela IV). Quanto aos resultados dos testes bacteriológicos para identificação e isolamento da $Y$. pestis, o bacilo foi encontrado tanto nas espécies sensíveis (Bolomys lasiurus, Oryzomys subflavus e Holochilus sciureus) quanto na resistente (Rattus $r$. frugivorus). Todos os isolamentos foram realizados no mês de setembro de 1986, quando o bacilo da peste foi também isolado de material de origem humana.

As três cepas humanas produzem nas cobaias reaçōes semelhantes às observadas por Karimi et al. (1974a) nas cepas originadas dos outros focos do Brasil. A cepa P.PB 862 mostrou-se tão virulenta para o roedor silvestre $O$. subflavus, quanto outras cepas estudadas em outras espécies de roedores susceptíveis (Karimi 
et al., 1974b; Almeida et al., 1986); entretanto os camundongos tiveram DL50 elevada. Karimi et al. (1974a) mostraram o comportamento particular das cepas de peste do Brasil em relação às diversas espécies de roedores. As 20 cepas isoladas no último surto da Paraiba, apresentam as mesmas características bioquímicas, fatores de virulência e sensibilidade aos antibióticos das cepas dos períodos anteriores.

Pelos resultados dos estudos realizados, concluímos que este surto de peste na Paraiba não apresentou fatores diferentes dos que ocorreram em passado recente na Chapada do Araripe/PE (Almeida et al., 1981; 1985) e Serra de Baturité/CE (Almeida et al., 1983).

\section{RESUMO}

Estudos bacteriológicos e sorológicos de um surto de peste no Estado da Paraíba, Brasil Foram realizados estudos bacteriológicos e/ou sorológicos para diagnóstico da infecção pestosa, em material obtido de 452 pacientes ( 48 positivos), 1.938 roedores e outros pequenos mamiferos ( 75 positivos), 4.756 cães (141 positivos) e 3.047 gatos (57 positivos), oriundos de 41 municípios localizados em toda a extensão da área paraibana do Planalto da Borborema. A infecção foi encontrada em 21 municípios.

Foram isoladas 20 cepas de Yersinia pestis de amostras coletadas de três pacientes e 17 roedores. Estas cepas apresentam caracteristicas bioquímicas, fatores de virulência, sensibilidade aos antibióticos e poder patogênico experimental semelhantes ao de cepas isoladas anteriormente.

Pelos estudos realizados, não foram observados, no surto de peste que eclodiu em setembro de 1986 na Paraiba, fatores diferentes dos observados nos outros focos do nordeste do Brasil.

Palavjas-chave: surto de peste - Yersinio pestis pacientes - roedores - carnívoros domésticos bacteriologia - sorologia

\section{REFERENCIAS}

ALVEIDA, A. M. P.; BRASIL, D. P.; CARVALHO, F: G. \& ALMEIDA, C. R., 1985. Isolamento de Yersinio pestis nos focos pestosos do Nordeste do Brasil no período de 1966 a 1982 . Rev. Inst. Med. Trop., Sāo Paulo, 27: 207-218.

ALMEIDA, A. M. P.; BRASIL, D. P.; CARVALHO, F. G. \& ALMEIDA, C. R., 1987a. Pesquisa de
Yersinia pestis em roedores e outros pequenos mamíferos nos focos pestosos do Nordeste do Brasil no período de 1966 a 1982. Rev. Saúde Pública, São Paulo, $21: 265-267$.

ALMEIDA, A. M. P.; BRASIL, D. P.; MËLO, M. E. B. LEAL, N. C. \& ALMEIDA, C. R., 1988. Importância dos carnívoros domésticos (cães e gatos) na epidemiologia da Peste nos focos do Nordeste do Brasil. Cadernos de Saúde Pública, RJ., 1:49-55.

ALMEIDA, A. M. P.; LEAL, N. C.; BRASIL, D. P. \& ALMEIDA, C. R., 1987b. Estudo comparativo entre as técnicas de hemaglutinação e aglutinação bacteriana no diagnóstico da peste humana. Rev. Microbiol., São Paulo, 18:126-130.

ALMEIDA, C. R.; ALMEIDA, A. M. P.; BRASIL, D. P.; DANTAS SOBRINHO, J. \& LEAL, M. A., 1986. Estudo do roedor Akodon arviculoides, Wagner, 1842 (Cricetidae). Importância nos focos pestosos do Brasil. Mem. Inst. Oswaldo Cruz, 81. 407-414

ALMEIDA, C. R.; ALMEIDA, A. M. P.; BRASIL, D. P.; LEAL, M. A. \& LIMA, J. W. O., 1983. Situaçâo da peste no Brasil no ano de 1982. XIX Congresso da Sociedade Brasileira de Medicina Tropical. Rio de Janeiro 149.

ALMEIDA, C. R.; ALMEIDA, A. M. P.; VIEIRA, J. B.; GUIDA, U. \& BUTLER, T., 1981. Plague in Brazil during two years of bacteriological and serological surveillance. Bull. Who, 59: 591-597.

BAHMANYAR, M. \& CAVANAUGH, D. C., 1976. Plague Manual. Geneva. WHO.

BAKER, E.; SOMMER, H.; FOSTER, L. E.; MEYER, E. \& MEYER, K. F., 1952. Studies on the immunization against plague. I. The isolation and characterization of the soluble antigen of Pasteurella pestis. J. Immunol., 68: 131-145.

BALTAZARD, M., 1968. Viagem de estudo ao Brasil para a organização de um proje to de pesquisas sobre a peste. Rev. Bras. Malariol. D. Trop., 20. $335-366$

BALTAZARD, M.; DAVIS, D. H. S.; DEVIGNAT, R.; GIRARD, G.; GOHAR, M. A.; KARTMAN, L.; MEYER, K. F.;PARKER, M. T.;POLLITZER, R.; PRINCE, F. M.; QUAN, S. F. \& WAGLE, P., 1956. Recommended laboratory methods for the diagnosis of plague. Bull. WHO, 14:457-509.

BAUER, A. W.; KIRBY, W. M. M.;SHERRIS, J. C. \& TURCK, M., 1966. Antibiotic susceptibility testing by a standardized single disk method. Am.J. Clin. Pathol., 45: 493-496.

BUTLER, T.; ALMEIDA, C. R.; ALMEIDA, A. M. P.; GUIDA, U. ; VIEIRA, J. B.; FRANCO, A. \& QUAN, T., 1980. Estudos sorológicos e experimentais da peste no Nordeste do Brasil, Rev. Bras. Malario. D. Trop., 32: 26-35.

BUTLER, T. \& HUDSON, B. W., 1977. The serological response to Yersinia pestis infection. Bull. WHO, 55: $39-42$.

FRLITAS, C. A., 1970. Considerações sobre a epidemiologia e profilaxia da peste. Bol. Of. Sanit. Pan. $A m$. 68: 393-402.

HUDSON, B. W. \& KARTMAN, L., 1967. The use of the passive hemagglutination test in Epidemiologic investigations of sylvatic plague in the United States. Bull. Wildife Dis. Assoc., 3: 50-59.

KARIMI, Y., 1978. Diagnostic rapide de l'infection pesteuse au laboratoirc. Bull. Soc. Path. Exot., 1: 45-48. 
KARIMI, Y.; ALMEIDA, C. R. \& ALMEIDA, A. M. P., 1974a. La peste experimentale chez les rongeurs du Brésil. Déductions Épidemiologiques. Bull. Soc. Path. Exot., Paris, 67: 591-601.

KARIMI, Y.; ALMEIDA, C. R.; ALMLIDA, A. M. P.; KLYVANFAR, A. \& BOURDIN, M., $1974 \mathrm{~b}$. Particularités des souches de $Y$. pestis isolées au Nord-Est du Brésil. Ann. Microbiol. Institut Pasteur, 125A: 243-246.

RLED, L. G. \& MULNCH, H., 1938. A Simple method for estimating 50 per cent end points. Amer. $J$. Hyg., 27: 493-497.

RUST, J. H.; CAVANAUGH, D. C.; O'SHITA, R. \& MARSHALL, J. D., 1971. The role of domestic animals in the epidemiology of plague. I. Experimental infection of dogs and cats. J. Inf. Dis., 124: 522-526.

WORLD HEALTH ORGANIZATION, 1970. Technical Report Series. (WHO, Expert Committee on Plague, Fourth Report), 447:23-25. 